\title{
Cordyceps sphecocephala and a Hymenostilbe sp. infecting wasps and bees in Thailand
}

\author{
NIGEL HYWEL-JONES* \\ National Centre for Genetic Engineering and Biotechnology, National Science and Techrology Development Agency, Ministry of Science, Technology \\ and Environment Building, Rama VI Road, Bangkok, 10400, Thailand
}

Cordyceps sphecocephala and a Hymenostilbe sp. were recorded from Hymenoptera (wasps and bees) in natural forest in Thailand. These were isolated from hyphal bodies, ascus part-spores and from conidia. The possible relationship between the two fungi is discussed. These records are compared with other collections from around the world.

Sphaeria sphecocephala was described by Klotzsch and published by Berkeley (1843) from wasps in Central America. S. sphecocephala Klotzsch ex Berk. was later transferred to Cordyceps as Cordyceps sphecophila Berk. \& M. A. Curtis. Mains (1958) noted that C. sphecocephala 'has frequently been given the name C. sphecophila apparently due to an error in publication by Berkeley and Curtis, who cited Tulasne but changed the name' of the epithet. Cooke (1892) noted problems concerning the spelling of the epithet and to prevent an 'unwarrantable multiplication of synonymy' chose to accept Cordyceps sphecocephala Klotzsch as the correct citation. This was accepted by Petch (1933; 1937). However, based upon the epithet provided by Klotzsch and based upon the currently accepted genus, the earliest correct citation is C. sphecocephala (KIotzsch) Sacc.

Petch (1937) considered C. sphecocephala to be the teleomorph of Isaria sphecophila Ditmar which he transferred to Hymenostilbe. Consequently, in a review of teleomorphanamorph connections, Kendrick \& DiCosmo (1979) listed $H$. sphecophila as the anamorph of $C$. sphecocephala citing Petch (1937; 1948). However, previously, Mains (1950) and Samson \& Evans '(1975) had considered Petch's Hymenostilbe as doubtful.

Petch (1932), Kobayasi (194I) and Mains (1958) discussed C. sphecocephala and several related species but came to separate conclusions on synonymy. In the last three years a large collection of Cordyceps and Hymenostille on wasps and bees in tropical forest in Thailand has been made. These specimens, and cultures derived from them, provide new information on Cordyceps sphecocephala and its possible relationship with a previously unaccepted Hymenostilbe.

* Address for correspondence: National Biological Control Research Centre, P.O. Box 9-52, Kasetsart University, Bangkok 10900, Thailand.

\section{MATERIALS AND METHODS}

Surveys were made of the leaf litter of the forest floor at Khao Yai National Park over a three year period throughout the year and sporadically at other National Parks in Thailand. Collections of infected insects were returned to the laboratory for processing. Isolations were made on Potato Dextrose Agar from abdominal hyphal bodies, ascus part-spores and from conidia. Slides were prepared for microscopic examination using an Olympus $\mathrm{BH}$ microscope with a drawing tube.

\section{RESULTS}

\section{Distribution of the fungi in Thailand}

All specimens were lying loose in, or on, moist leaf litter in the rainy season between May and October. All were found in forest between 100 and $1600 \mathrm{~m}$ above sea level. Forest types included tropical monsoon evergreen forest (at Khao Yai), tropical monsoon deciduous forest (at Sam Lan) and submontane evergreen forest (at Doi Inthanon). Many were found on their backs giving the impression they had fallen from the surrounding vegetation at death.

\section{Description of the Cordyceps and Hymenostilbe specimens from Thailand}

The inside of the host was packed with white, oval, hyphal bodies, $20-30 \mu \mathrm{m}$ by $10-20 \mu \mathrm{m}$. A single stroma arose from any point on the insect but usually from between the head and thorax. This was up to $45 \mathrm{~mm}$ long including the head. Where these contacted a substrate such as leaves or twigs, rhizoidal growth fixed the stroma to this substrate.

The diameter of the stalk was 150-800 $\mu \mathrm{m}$ consisting of parallel strands of septate, tightly packed hyphae, 4-o um 


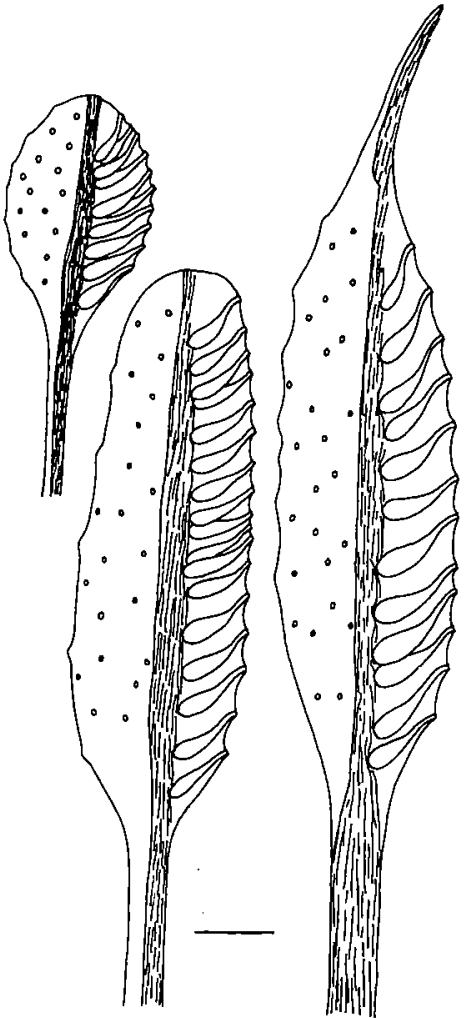

Fig. 1. Three fertile heads of $C$. sphecocephala showing the external appearance (left side) and internal appearance (right side). Scale bar, $1 \mathrm{~mm}$.

across. There was no evidence of branching. Fertile heads were terminal, variable in size and shape, the smallest being $2.2 \times 1.2 \mathrm{~mm}$ and the largest $11 \times 1.9 \mathrm{~mm}$ (Fig. 1) but mostly in the range $4-8 \times 1 \cdot 4-1 \cdot 8 \mathrm{~mm}$. Heads were citriform to cylindric in shape, attenuating to a bent tip. Both stalk and head were ochraceous to cream yellow.

Dissection of the head showed the colour was confined to the outer walls. The interior contained perithecia with walls of tightly interwoven, hyaline hyphae in a loose context of hyaline cells around a central core which was an extension of the stalk (Fig. I). Perithecia were oblique to the walls of the fertile head but with a distinctive curve on the neck ending almost at right-angles to the outer wall of the head. Perithecia were large $880-1000 \times 200-260 \mu \mathrm{m}$ with no evidence of a hamathecium. All seemed to mature at the same time. However, within each perithecium asci were found at different stages of development.

Asci were hyaline, filiform, at least $700 \mu \mathrm{m}$ long and up to $7 \mathrm{\mu m}$ diameter with a prominent apical cap (Fig. 2). A thickened plug was sometimes seen at the tip of the cap above the central canal (Fig. 2). This feature was not constant within or between specimens and did not appear to be related to the state of ascus development. At maturity, ascospores broke readily into hyaline, fusoid part-spores, $10-14 \times 1.5-2.5 \mu \mathrm{m}$ (Fig. 2).

Most specimens examined, and especially larger forms, were very mature and devoid of part-spores. For others, pressure applied to the fertile head was often enough to release part-spores into water. Natural release of part-spores was not observed.

On some specimens there were eggs on the stroma and dipteran larvae within the Cordyceps head. Larvae fed upon perithecia and stromatal contents within the fertile head. When this happened it was not possible to find any healthy perithecia or any spores.

When the Cordyceps head was damaged, it was possible for new growth to occur. This was either from the point of

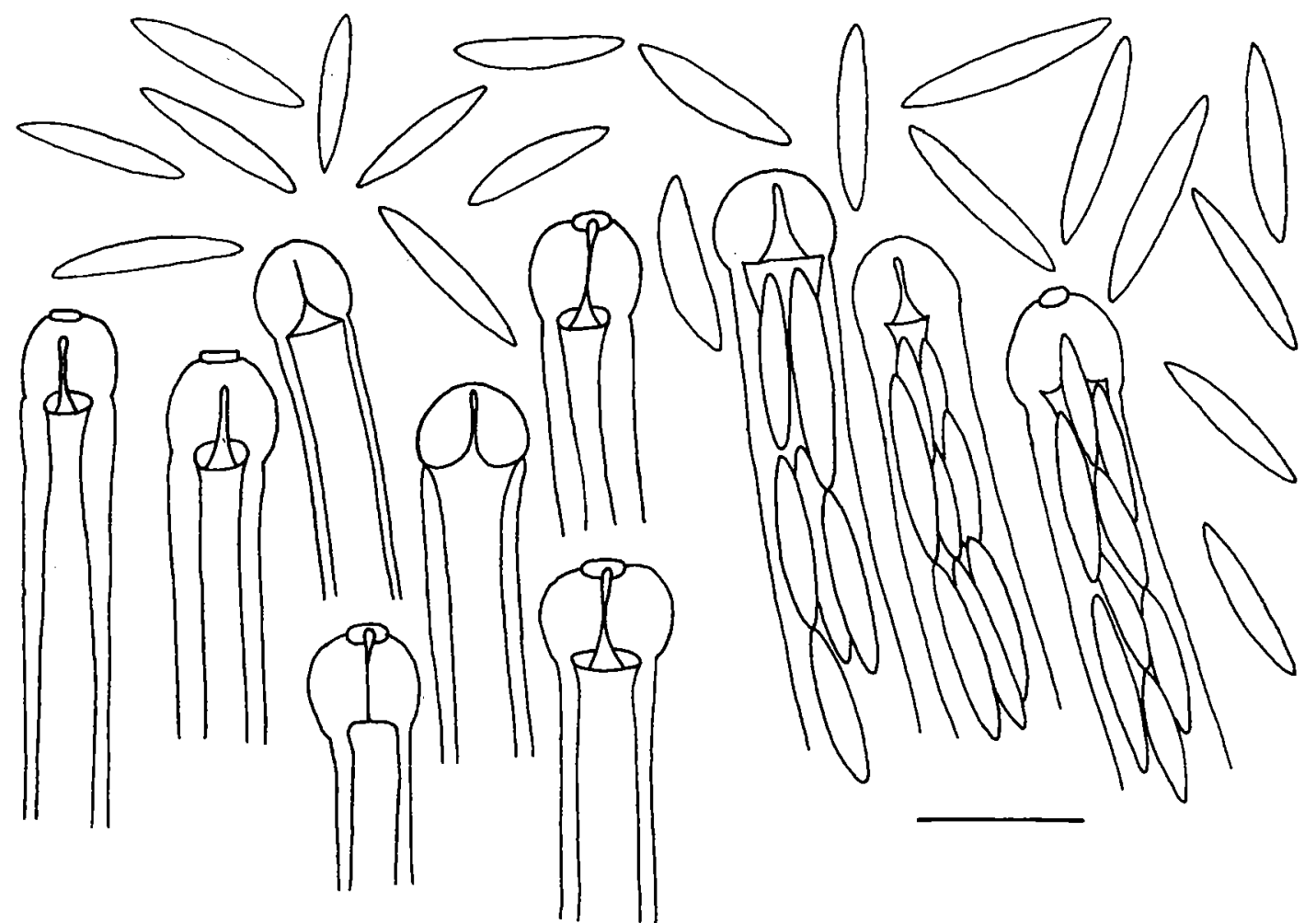

Fig. 2. Tips of seven immature asci and three mature asci with examples of part spores. Scale bar, $10 \mu \mathrm{m}$. 


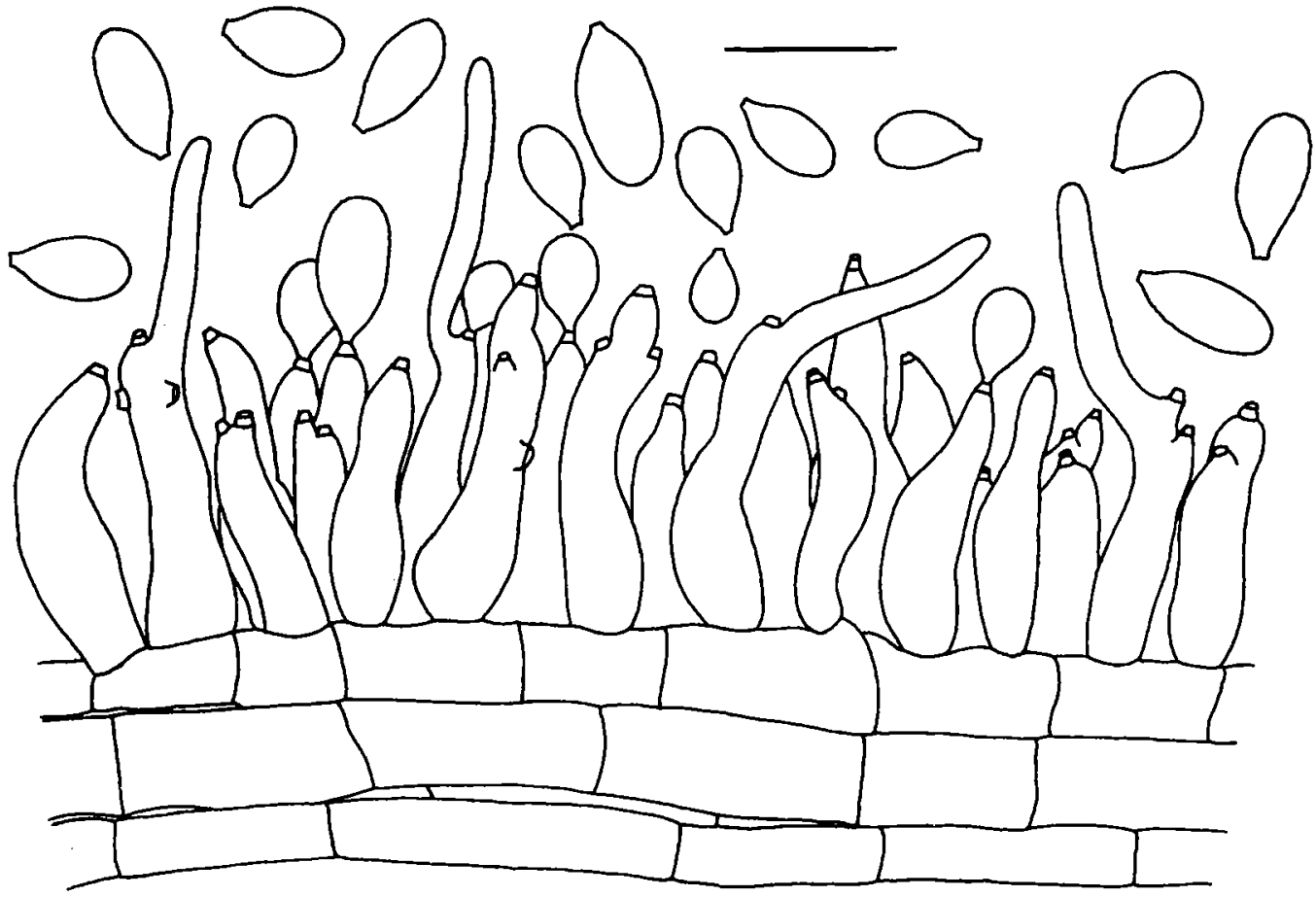

Fig. 3. Part of the hymenial layer showing the conidiogenous cells and conidia of H. sphecocephala. Scale bar, $10 \mu \mathrm{m}$.

damage or from the base of the fertile head. The new growth, however, appeared to be sterile and there was no evidence of a regrowth of the teleomorph or the development of an anamorph.

No evidence was found of an anamorph on the same stroma as the teleomorph. Occasionally, specimens were found which in all respects of habit matched the Cordyceps form. These differed in not producing a fertile teleomorph but in producing a stroma which remained the same diameter throughout rounding only at the tip. Examination revealed the presence of a Hymenostilbe state on the terminal part of the stroma.

The conidiogenous cells were very variable in size and shape as is typical of the genus. They were cylindrical, $10-20 \times 3-6 \mu \mathrm{m}$ with one to three stout denticles (Fig. 3). A notable feature of the conidiogenous cells were long sterile extensions up to $25 \mu \mathrm{m}$ which gave the stroma a markedly setulose appearance at low power. Conidia were broadly clavate, strongly apiculate and 3-10 $\times 3-4.5 \mu \mathrm{m}$.

Specimens examined: All specimens were on adult wasps (Hymenoptera) except for one record on a bee. These were deposited in the insect-fungus collection at NBCRC with the author's codes.

Teleomorph: NHJ595.01, Khao Yai - Phakrajai, 24 Sept. 1991, N. L. Hywel-Jones; NHJ623.04, Khao Yai - Heo Sawat, 15 Oct. 1991, N. L. Hywel-Jones \& K. Jones; NHJ804.02, Khao Yai - Heo Sawat road marker km 44.8, 25 June 1992, N. L. Hywel-Jones, L. Manoch, A. Rongchitprapas \& S. Sivichai; NHJ858.04, Khao Yai-Gong Giao, 28 Aug. 1992, N. L. Hywel-Jones, A. Rongchitprapas \& S. Sivichai;

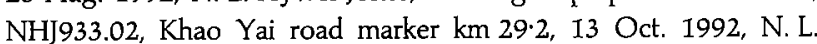
Hywel-Jones; NHJ948, NHJ953.03 \& NHJ953.04, Sam Lanwaterfall, 15 Oct. 1992, N. L. Hywel-jones, A. Rongchitprapas \& S. Sivichai; NHJ1070, NHJ1075, Khao Yai-Phakrajai, 27 May 1993, N. L. Hywel-Jones \& R. Nasit; NHJ1206, Khao Yai-Heo Narok, 22
June 1993, N. L. Hywel-Jones \& R. Nasit; NHJ1224, Khao Yai - Heo Narok, 29 June 1993, N. L. Hywel-Jones, R. Nasit, R. Plomhan \& S. Thienhirun; NHJ1316 \& NHJ1743 \& NHJ1752, Khao Yai-Gong Giao, 6 Aug. 1993, N. L. Hywel-Jones, R. Nasit, S. Sivichai \& R. Plomhan; NHJ1800, NHJ1801, NHJ1807 \& NHJ1822, Khao YaiHeo Narok, 10 Aug. 1993, N. L. Hywel-Jones, R. Nasit \& S. Sivichai; NHJ2133, Khao Yai - Gong Giao, 9 Sept. 1993, N. L. Hywel-Jones, R. Nasit, S. Sivichai \& S. Thienhirun; NHJ2199, Doi Inthanon road marker km 25.5, 26 Sept. 1993, N. L. Hywel-Jones, K. Auncam, R. Nasit, S. Thienhirun \& A. J. S. Whalley.

Anamorph: NHJ1332, Khao Yai - Phakrajai on an adult bee, 6 July 1993, S. Sivichai, L. Tangchit \& C. Yomsopit; NHJ1741, Khao Yai Phakrajai, 6 Aug. 1993, N. L. Hywel-Jones, R. Nasit \& S. Sivichai; NHJ1858, Khao Yai road marker km 44.8, 17 Aug. 1993, N. L. Hywel-Jones, R. Nasit \& S. Sivichai.

Immature: NHJ787:01, Khao Yai road marker km 29·2, 6 June 1992, N. L. Hywel-Jones.

\section{Culture of the fungi}

Cultures were started from hyphal bodies, part-spores, and from conidia. Initial isolations were on PDA. Part-spores and conidia germinated in the dark at $22^{\circ} \mathrm{C}$ within $20 \mathrm{~h}$. Hyphal bodies germinated after $5 \mathrm{~d}$ under the same conditions apart from brief periods of light each day for examination.

Isolates are stored in the NCGEB insect-fungus collection. Isolate numbers coincide with the herbarium numbers given to specimens. Isolates derived from part-spores were NHJ595.01, $623.04,804.02,948,953.02,953.03,1743$ and 1800 . Isolates derived from conidia were $\mathrm{NHJ} 1332,1741,1752$ and 1858 . Isolate NHJ787.01 was derived from abdominal hyphal bodies.

Isolations from all three sources were sterile but morphologically indistinguishable. Growth was very slow and 
stromatic on PDA reaching $33 \mathrm{~mm}$ in 14 wk at $22^{\circ}$. Cultures were hyaline to pale grey brown with only sparse aerial mycelium. Some isolates developed an irregular, immersed, hyaline margin in contrast to the regular, immersed, hyaline margin that was also noted. The reverse was grey-white to pale grey brown. Several stout synnemata developed after $3 \mathrm{wk}$. They were silky pale cream and up to $400 \mu \mathrm{m}$ diam. and appeared similar to the stromata on the hosts. There was no sign of either a teleomorph or an anamorph developing on these stromata.

\section{DISCUSSION}

Since Torrubia first noted the appearance of infected wasps in Cuba in 1749 (see Samson, Evans \& Latgé, 1988) there have been many reports of Cordyceps infecting wasps around the world. Petch (1932) noted Cordyceps gentilis (Ces.) Sacc. on a hornet sent to him from Thailand. He considered $C$. gentilis distinct from C. sphecocephala $(=$ C. sphecophila in Petch's early writings) noting the 'longer, more acute head' of C. gentilis which contrasted with the 'ovoid or narrow-oval, and acute' head of $C$. sphecocephala.

Petch (1933) later described the shape of the head of $C$. sphecocephala as variable and used the description and measurements of the Thai specimen of $C$. gentilis in support. In this paper, he considered $C$. gentilis synonymous with $C$. sphecocephala along with $C$. lachnopoda Penz. \& Sacc., C. oxycephala Penz. \& Sacc., C. puiggarii Speg. and C. thyrsoides Möller. Kobayasi (1941) described C. sphecocephala from Japan. He regarded $C$. oxycephala to be distinct from $C$. sphecocephala (based on the shape of the head) and considered C. gentilis a synonym of the former species along with $C$. puiggarii. Later, Mains (1948) showed that C. puiggarii was not the same as these wasp Cordyceps.

Mains (1958) re-described Cordyceps sphecocephala from a substantial collection of specimens from North America and concluded that there was much variation in the overall morphology which manifested itself in the many different names given to what, essentially was a single species. All early observations put weight upon gross morphology as a separator of species with little attention being paid to microscopic features.

The work of Mains (1958) and the present observations from Thailand, based upon substantial collections within welldefined geographical regions, suggest there is a single species, C. sphecocephala which shows gross morphological variation but is constant in microscopic detail. While the microscopic characteristics of $C$. sphecocephala in Thailand showed little variation there were large differences in the shape and size of the fertile head (Fig. I). The Thai records suggest that maturity of the specimen, size of the host, micro-habitat conditions such as humidity and damage re-growth may all affect the form of the head.

Ditmar (1817) described and figured Isaria sphecophila from a hornet in Germany noting that the upper part of the simple, brown synnema was pilose and darkened. His figures indicate a minutely setulose condition with globose, hyaline conidia. Speare (1920) discussed Ditmar's fungus and, on the basis of the illustrations, suggested that this should be placed in Hirsutella. Petch (1932) agreed noting that it (Ditmar's fungus) 'does not agree with a Hymenostilbe'.

Later, Petch (1937) found a conidial state on an ichneumon wasp in England and considered this identical to Ditmar's fungus and concluded 'that Isaria sphecophila Ditm. is a Hymenostilbe and that it is the conidial stage of Cordyceps sphecocephala (K1.) Cooke'. The description given by Petch (1937) was brief with no illustrations. However, he noted the synnemata were cream-coloured and $1.75 \mathrm{~mm}$ long. Ditmar's fungus had brown synnemata which were $90 \mathrm{~mm}$ long. Specimens examined by Petch (1937) had clavate or narrowoval conidia in contrast to the globose conidia of Ditmar's fungus.

Mains (1950) noted for $H$. sphecophila that it 'is doubtful whether it is Ditmar's fungus'. Samson \& Evans (1975) accepted nine species of Hymenostilbe and, like Mains (1950), they also regarded $H$. sphecophila as doubtful. No type specimen remains of Ditmar's fungus but it is possible this is Hirsutella saussurei Speare which also has long, brown synnemata and conidia that appear globose in a mucous coat.

In spite of these doubtful records, Kendrick \& DiCosmo (1979) listed H. sphecophila as the anamorph of C. sphecocephala citing Petch $(1937 ; 1948)$. Furthermore, in their scheme the $C$. sphecocephala- $H$. sphecophila association was coded 2.3.1 suggesting the link was documented with experimental evidence of one morph developing from the other in culture. There is no evidence in either of the cited works by Petch that he ever attempted to culture either fungus. Indeed, Petch (1948) was merely a listing of British entomogenous fungi in which he noted the association based upon his 1937 study of herbarium material. Furthermore, it seems as though there have been no attempts to isolate either fungus until now.

As Petch (1937) cites only a single record associating the two species, under the Kendrick \& DiCosmo scheme it would have been better to code this association at a lower level of 2.2.1 - documented but circumstantial evidence of association based on a single observation of co-habitation. But as earlier workers (Mains, 1958; Samson \& Evans, 1975) had already raised doubts as to whether Ditmar's fungus could be considered the same as Petch's Hymenostilbe records associated with $C$. sphecocephala, it would be prudent to say that a Hymenostilbe may be associated with $C$. sphecocephala based upon Petch's 1937 writings.

The Hymenostilbe sp. on wasps from Thailand had a setulose appearance due to sterile extensions of the conidiogenous cells. This feature has not been described before for Hymenostilbe (Samson \& Evans, 1975) but the conidial state is clearly assignable to Hymenostilbe and not Hirsutella. The current work showed that $C$. sphecocephala is present on wasps in Thailand and that a Hymenostilbe sp. not considered by Samson \& Evans (1975) is also present on wasps and bees in the same micro-habitats. Furthermore, it showed that isolations from the Cordyceps and Hymenostilbe are morphologically similar, suggesting they may be linked.

Until more collections can be made it is proposed that the Hymenostilbe sp. found in Thailand is possibly an anamorph of C. sphecocephala based upon its co-habitation and morphological similarity in culture and may be the same as the Hymenostilbe specimens examined by Petch (1937) and Mains 
(1950). It is unlikely that the Hymenostilbe from Thailand is the same as Ditmar's fungus from Germany.

The National Research Council of Thailand is thanked for providing the opportunity to do this work. Dr Banpot Napompeth and his staff at the NBCRC are especially thanked for providing me with a friendly atmosphere in which to work. Miss Rungtip Nasit and Somsak Sivichai proved adept at finding many of these specimens. Mrs Surang Thienhirun of the Royal Forestry Department is thanked for her assistance.

\section{REFERENCES}

Berkeley, M. J. (1843). On some entomogenous Sphaeriae. Hooker's London Joumal of Botany 2, 205-211.

Cooke, M. C. (1892). Vegetable Wasps and Plant Worms. Society for Promoting Christian Knowledge: London.

Ditmar, L. P. F. (1817). Die Pilze Deutschlands. Flora Abb nach der Natur von Jacob Sturm 3 Heft 4, I-130.
Kendrick, W. B. \& DiCosmo, F. (1979). Teleomorph-anamorph connections in Ascomycetes. In The Whole Fungus: The Sexual-Asexual Synthesis, vol. I (ed. W. B. Kendrick), pp. 283-395. National Museum of Canada: Toronto Kobayasi, Y. (1941). The genus Cordyceps and its allies. Science Report of the Tokyo Bunrika Daigaku (Section B. no. 84) 5, 53-260.

Mains, E. B. (1948). Entomogenous fungi. Mycologia 40, 402-416.

Mains, E. B. (1950). Entomogenous species of Akanthomyces, Hymenostilbe and Insecticola in North America. Mycologia 42, 566-589.

Mains, E. B. (1958). North American entomogenous species of Cordyceps. Mycologia 50, 169-222.

Petch, T. (1932). Notes on entomogenous fungi, 22-48. Transactions of the British Mycological Society 16, 209-245.

Petch, T. (1933). Notes on entomogenous fungi, 49-75. Transactions of the British Mycological Society 18, 48-75.

Petch, T. (1937). Notes on entomogenous fungi, 101-134. Transactions of the British Mycological Society 21, 34-67.

Petch, T. (1948) A revised list of British entomogenous fungi. Transactions of the British Mycological Society 31, 286-304.

Samson, R. A. \& Evans, H. C. (1975). Notes on entomogenous fungi from Ghana. 3. The genus Hymenostilbe. Proceedings, Koninklijke Nederlandse Akadamie van Wetenschappen, Series $C$ 78, 73-80.

Samson, R. A., Evans, H. C. \& Latgé, J. P. (1988). Atlas of Entomopathogenic Fungi. Springer, Heidelberg. 189pp.

Speare, A. T. (1920). On certain entomogenous fungi. Mycologia 12, 62-76. 